\title{
A descolonizar las metodologías. Investigación y pueblos indígenas ${ }^{*}$
}

\author{
Linda Tuhiwai Smith \\ Traducción de Kathryn Lehman
}

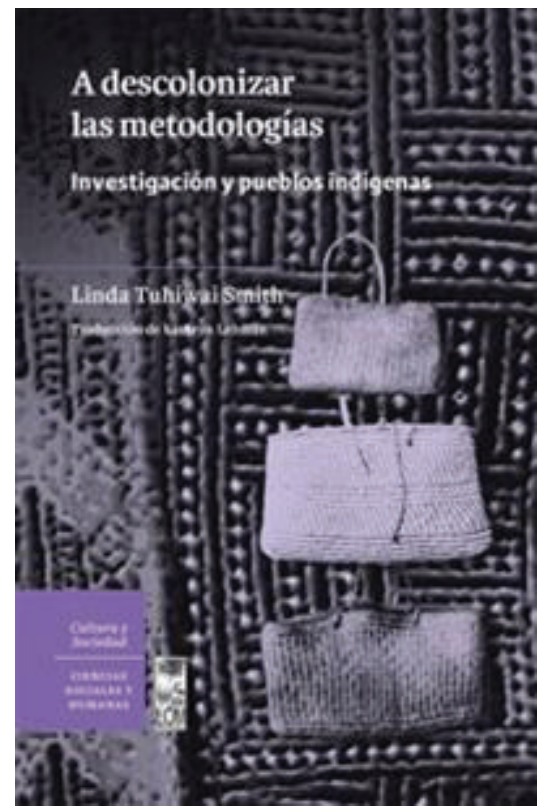

\section{Felipe Guerra-Schleef*}

Maori y Profesora de Educación Indígena en la Universidad de Waikato en Hamilton, Nueva Zelanda, Linda Tuhiwai Te Rina Smith publicó por primera vez su libro Decolonizing Methodologies en 1999, el que se transformó a partir de ese momento en una obra de referencia para el

* 2016. Santiago: LOM. 308 páginas.

** Observatorio Ciudadano (http://observatorio.cl). Correo electrónico: felipe.guerra.schleef@gmail.com 
movimiento indígena en gran parte del mundo, fundamentalmente en países angloparlantes. Ahora, LOM Ediciones hace accesible este trabajo reeditado y actualizado para los pueblos indígenas, investigadores (indígenas y no indígenas), estudiantes y organizaciones de países de habla hispana.

A descolonizar las metodologías es uno de los esfuerzos más serios de articulación de uno de los problemas más complejos para los pueblos indígenas de todo el mundo: la relación de estos pueblos con la investigación institucionalizada en un sistema global de imperialismo y relaciones de poder asimétricas. En este sentido, la investigación dista de ser un ejercicio académico inocuo donde lo único que está en juego es el desenvolvimiento de la verdad y el conocimiento. En palabras de la propia autora:

A descolonizar las metodologías se ocupa ya no de la técnica real de selección de un método, sino en mayor medida del contexto en el cual se conceptualiza y proyectan los problemas de investigación, y de las implicancias de la investigación para sus participantes y las comunidades de estos (2016: 11).

Si bien este libro fue pensado, ante todo, para académicos, activistas y estudiantes indígenas de todo el mundo, interesados en desarrollar una investigación que resulte significativa para sus pueblos, comunidades y organizaciones, su enfoque hace que las preguntas y discusiones que se construyen sean capaces de interpelar a académicos, activistas y estudiantes indígenas y no indígenas provenientes de todas las disciplinas y ciencias. A lo largo del prólogo, introducción, sus doce capítulos y apartado final, Linda Tuhiwai Smith invita al lector a reflexionar sobre el papel de la investigación en el proceso de colonización de los pueblos indígenas, su vínculo con el imperialismo global, su impacto en los saberes, el rol de la investigación en el movimiento social de los pueblos indígenas, los desafíos que enfrentan los investigadores indígenas y no indígenas que deciden investigar en los márgenes, así como la necesidad y retos de articular una agenda de investigación desde los mismos pueblos, donde ellos pasen de ser objetos de investigación (colonizados) a ser los protagonistas de su propio destino. En este sentido, descolonizar es ante todo un ejercicio de autodeterminación, de deconstrucción y desmonte de 'las historias', con el objeto de revelar los contextos subyacentes que, a menudo, solo conocemos de manera intuitiva.

La investigación está altamente institucionalizada a través de las disciplinas y los campos del conocimiento, por medio de las 
comunidades, grupos de interés y la academia. Además, la investigación es parte integral de la estructura política: es financiada por los Estados, corporaciones, organizaciones científicas y programas de desarrollo. Los pueblos colonizados son concientes de ello desde mucho antes de que los investigadores se interesaran en estos temas: "Los modos en que la investigación científica ha sido partícipe en los peores excesos cometidos por el colonialismo, continua siendo una historia asiduamente recordada por muchos pueblos colonizados del mundo" (2016: 19).

Sin perjuicio de lo anterior, la autora reconoce en la investigación un territorio de lucha. Muchos investigadores (probablemente la mayoría) se ven a sí mismos emprendiendo proyectos que aportarán al bien común de la humanidad, la transformación social o la emancipación de un grupo oprimido. En palabras de la autora, "creer en el ideal de que beneficiar a la humanidad es efectivamente el resultado principal de una investigación científica es tanto un reflejo ideológico como de entrenamiento académico" (2016: 21). Esto supone saber posicionarnos frente a la investigación, establecer direcciones estratégicas y hacer las preguntas apropiadas. No existen espacios neutrales para el tipo de trabajo y compromiso requeridos para asegurar que los conocimientos tradicionales indígena florezcan a lo largo de generaciones venideras y permanezcan íntimamente ligados a sus pueblos como vía de pensamiento y razón de ser.

De esta manera, $A$ descolonizar las metodologías se pregunta sobre la posibilidad y condiciones de desarrollar una agenda de investigación que responda a las necesidades de los grupos tradicionalmente marginalizados en las sociedades de los países coloniales. Si bien el libro no entrega una respuesta general a las preguntas planteadas (probablemente ese no es su propósito), contiene un relato consistente sobre cómo el pueblo Maori hizo frente a estos desafíos en su contexto. De esta manera, las respuestas que ofrezcamos a estas preguntas pasan por conocer las tramas particulares donde nos desenvolvemos los investigados y activistas preocupados por generar información que sirva a las necesidades de nuestros pueblos y comunidades. Como señala Linda:

La crítica del positivismo hecha por las teóricas feministas, las minorías étnicas y los indígenas han surgido de la experiencia de la gente que ha sido estudiada, investigada, escrita y definida por científicos sociales. Es desde esta posición de "investigados" que los pueblos maori también han resistido y desafiado la investigación de las ciencias sociales. Este desafío ha hecho frente tanto a 
asuntos metodológicos como a preocupaciones epistemológicas, es decir, las técnicas de investigación y las premisas sobre el conocimiento que subyacen en la investigación. Las críticas plateadas por los pueblos maorí sitúan los debates teóricos del mundo en general dentro del contexto local de Nueva Zelandia (2016: 228).

En el contexto de Nueva Zelandia, el establecimiento del Tribunal de Waitangi y el Te Kohanga Reo fueron de gran importancia y determinantes en el desarrollo de la investigación propiamente maori. El Tribunal de Waitangi fue creado en 1975 con el objetivo de oír los reclamos de los maori sobre las contravenciones del Tratado de Waitangi, firmado en 1840 entre jefes maori y la Corona Británica (una historia que se repite en muchos pueblos colonizados). La presentación de demandas ante este Tribunal -que aplica e interpreta oficialmente un texto fundacional del Estado neozelandés- ha supuesto el establecimiento de un foro jurisdiccional, especializado e intercultural, que ha impulsado la investigación maori. La litigación requiere de un trabajo de documentación y fundamentación que ha permitido recuperar textos históricos y relatos orales hasta hace poco ignorados por la Corona. Por su parte, Te Kohanga Reo se construyó como una iniciativa de desarrollo maori, destinada a mantener y fortalecer la lengua madre y su filosofía dentro del marco cultural inspirado por los abuelos en 1982. En este sentido, la relación entre el pueblo Maori y el Estado neozelandés puede parecer un caso único y paradigmático. Pero qué contexto no lo es.

Si bien el trabajo conceptual y la investigación en relación con el conocimiento ancestral maori (matauranga maori), desde los propios investigadores maori, parece florecer dentro de las instituciones propias de este pueblo, también lo hace en una amplia variedad de áreas y disciplinas como la salud, la ciencia, la educación, el arte y el derecho, solo por mencionar algunas. Los investigadores maori han desarrollado su propia aproximación a la investigación, con el propósito de seleccionar las técnicas e instrumentos culturalmente pertinentes para investigar en sus comunidades. Esto se ha conocido como la investigacion Kaupapa Maori, la que se ha convertido en una forma culturalmente fiable de estructurar suposiciones, valores, conceptos, orientaciones y prioridades en la investigación, que le permite a las comunidades maori recobrar el control de la actividad investigativa. El desarrollo del enfoque Kaupapa Maori ha dado lugar al establecimiento de una comunidad de académicos maori, así como una extensa e interesante discusión sobre los principios, condiciones y fundamentos epistemológicos de una investigación indígena realizada desde los propios pueblos indígenas. 
El libro nos relata la fructífera actividad académica y de debate concitada en la investigación maori en Nueva Zelandia. Sin embargo, también expone los desafíos pendientes entre las múltiples capas de la lucha de este pueblo por la descolonización. En efecto, tal como sostiene Linda, si bien la actividad investigativa maori ha consolidado los espacios que ha ocupado:

Tal nivel de actividad e institucionalización está en deuda con el activismo, que se remonta a varias décadas atrás. Los tipos de activismo requerido para que cada generación proteja y alimente el conocimiento indígena han variado desde la acción política directa y las protestas para defender la lengua maori, las acciones en juzgados, ocupaciones de tierra y reclamaciones al Tribunal de Waitangi por medio de la implementación de programas que sustentarían el conocimiento en las instituciones públicas. El conocimiento tradicional indígena está revitalizándose en espacios creados por el activismo (2016: 293).

Para Linda Tuhiwai Smith, en un mundo ideal, "donde los pueblos indígenas ejercieran un cierto poder político y económico, los activistas serían capaces de recurrir a su comité de expertos, con su oficina principal cerca de las demás instituciones del poder" (2016: 294). La experiencia del pueblo Maori nos enseña cómo la investigación desde los pueblos indígenas nace y se desarrolla a partir de las necesidades evidenciadas por el activismo. A descolonizar las metodologías también nos habla de cómo un pueblo indígena desarrolla una estrategia tecnocrática para afrontar los desafíos de la descolonización en su contexto. Esto abre nuevas preguntas sobre la coherencia de un proyecto como este y nos demuestra que la autodeterminación está llena de matices y se manifiesta en formas complejas. 
